\title{
Baseline endothelial-related biomarkers in hemodialysis patients and risk of developing severe SARS-Cov-2 infection
}

\author{
Cícero Abdon Malheiro Gomes ${ }^{1} \cdot$ Bianca Matos de Carvalho Borges ${ }^{2} \cdot$ Lucas Oliveira Lemos $^{2}$. \\ Camilla Maroni Marques Freire de Medeiros ${ }^{3}$. Paula Roberta de Lima ${ }^{4} \cdot$ Gdayllon Cavalcante Meneses $^{4}$. \\ Alice Costa Martins ${ }^{4}$. Candice Torres de Melo Bezerra Cavalcante ${ }^{2} \cdot$ Marcelo Borges Cavalcante $^{2}$. \\ Alexandre Braga Libório ${ }^{1}$
}

Received: 2 June 2021 / Accepted: 27 June 2021 / Published online: 19 July 2021

(c) Italian Society of Nephrology 2021

Coronavirus disease 2019 (COVID-19) represents a major challenge for health systems worldwide, due to its pandemic spread and its high mortality rate. By mid-January 2021, COVID-19 had caused more than 2 million deaths worldwide. Brazil is one of the countries with the highest number of infected patients (more than 8 million) and deaths $(\sim 210,000)$ [1]. Direct viral infection of the endothelial cell and diffuse endothelial inflammation were demonstrated in a series of patients with COVID-19, with subsequent organ ischemia and a procoagulant state [2].

Here, we describe preliminary findings from a cohort of maintenance hemodialysis patients with previous baseline measurement of endothelium-related biomarkers. This cohort was first created to evaluate the association of endothelial derangement with cognitive derangement [3]. Among the endothelium-related biomarkers, we have chosen four that comprise different endothelial functions/structures: intercellular adhesion molecule-1 (ICAM-1), vascular cell adhesion protein-1 (VCAM-1), which is related to endothelial cell activation; angiopoietin-2 (AGPT2), an endothelial growth factor that promotes polymorphonuclear cell infiltration and induces endothelial cell apoptosis; and syndecan-1,

$\triangle$ Alexandre Braga Libório

alexandreliborio@yahoo.com.br

1 Medical Sciences Postgraduate Program, Universidade de Fortaleza, UNIFOR, Avenida Abolição, 4043 Ap 1203,

Fortaleza, Ceara 60165-082, Brazil

2 School of Medicine, Universidade de Fortaleza, UNIFOR, Fortaleza, Ceará, Brazil

3 Medical Sciences Postgraduate Program, Department of Clinical Medicine, Universidade Federal do Ceará, Fortaleza, Ceará, Brazil

4 Clinical and Toxicological Analysis Department, School of Pharmacy, Federal University of Ceará, Fortaleza, Ceará, Brazil a newly explored marker of endothelial glycocalyx derangement, that has been reported as increased in hemodialysis patients [4].

SARS-Cov-2 infection is associated with several vascular complications, including pulmonary thrombosis, contributing to its severity and mortality [5].Endothelial dysfunction can also lead to vasoconstriction with subsequent ischemia, inflammation with tissue edema, and a procoagulant state [2]. Our main objective was to evaluate whether these biomarkers predict the risk of developing severe COVID-19 in maintenance hemodialysis patients.

We gathered data on all our adult patients on maintenance hemodialysis. By the end of August 2020, sera from patients without a previous COVID-19 diagnosis were tested using the Mybiosource SARS-CoV-2 IgG assay. In September 2019, these patients had blood samples collected as part of a previous study evaluating cognition and endothelial alterations [3]. At that moment, endothelium-related biomarkers were measured. The present study was approved by the institutional review board of the Ethical Committee of Universidade de Fortaleza and the original cohort by Universidade Federal do Ceará.

Furthermore, the following variables were gathered: age, gender, arterial hypertension, diabetes mellitus, cardiovascular disease (coronary artery disease and/or peripheral vascular disease), dialysis vintage, body mass index (BMI) $>30 \mathrm{~kg} / \mathrm{m}^{2}$, hemoglobin, serum albumin and the endothelium-related biomarkers VCAM-1, ICAM-1, AGPT2 , and syndecan- 1 . The outcome was severe COVID-19, defined as SARS-Cov-2-related hospital admission based on the attending physician's judgment, or mortality due to COVID-19.

The study cohort consisted of 122 patients. Of these, 29 (23.8\%) had symptomatic COVID-19 diagnosed by RTPCR, 15/29 (51.7\%) required hospital admission and 6/29 
(21.4\%) died. Further 22/122 (18.0\%) patients had asymptomatic infection diagnosed only retrospectively by antibody testing by ELISA. These 51 patients ( 29 symptomatic and 22 asymptomatic COVID infection) were selected and included in the final analysis. The majority of patients were males $(\mathrm{n}=32 / 51,62.7 \%)$ and the mean age was $53.5 \pm 17.1$ years. The median dialysis vintage was 84 [12-144] months. The prevalence of arterial hypertension was $68.6 \%$ and diabetes mellitus was $49.0 \%$. Only four patients had BMI $>30 \mathrm{~kg} / \mathrm{m}^{2}$.

Patients with severe COVID-19 infection were older, had longer dialysis vintage and had more cardiovascular disease. No difference was observed regarding gender or systemic arterial hypertension diagnosis. Although no difference was observed at the baseline levels of ICAM, VCAM- 1 and AGPT-2 levels, syndecan-1 levels were higher in patients with severe COVID-19 than in those with asymptomatic/ non-severe COVID-19 see Table 1. Only syndecan-1 was correlated with clinical variables-age $\left(r_{s}=0.378, p=0.001\right)$ and dialysis vintage $\left(r_{s}=0.422, p<0.001\right)$.

Multivariate regression and mediation analyses [6] were performed to assess the hypothesized associations between clinical demographic characteristics and selected endothelial-related biomarkers with severe COVID-19. Age (OR 1.07 95\% CI 1.01-1.13, per each year) and dialysis vintage (OR $1.1095 \%$ CI 1.02-1.21, per each 10 month) remained significantly associated with severe COVID-19. However, after including baseline syndecan-1 levels in the model, neither variable was associated (age with OR 0.98
95\% CI 0.87-1.10 and dialysis vintage with OR $1.0895 \%$ CI 0.92-1.23) with severe COVID-19, and only syndecan-1 was independently associated with this outcome-OR 1.34 95\% CI 1.05-1.72, per each $10 \mathrm{ng} / \mathrm{mL}$.

Aiming to further explore the association between syndecan-1 and COVID-19 severity, we performed a mediation analysis. In the unadjusted analysis, the putative impact of age and dialysis vintage on COVID-19 severity seemed to be mediated by syndecan-1 levels. The direct effect was no longer significant on either age or dialysis vintage. After adjustment for confounders, the results were very similarsee Table 2.

In the present study, we performed a secondary analysis of a cohort of maintenance hemodialysis patients using endothelium-related biomarkers measured within 6-months before the SARS-Cov-2 pandemic. The presence of this cohort gave us the opportunity to evaluate whether the baseline endothelium status evaluated through several biomarkers would be associated with severe COVID-19. The main finding of our study is that baseline levels of syndecan-1 measured in hemodialysis patients before SARS-Cov-2 infection is associated with severe COVID-19. Moreover, our data suggest that endothelium glycocalyx derangement can be an important mediator of the increased risk of severe COVID-19 infection associated with age and dialysis vintage in maintenance HD patients.

Our cohort has a prevalence of COVID-19 infection of $41.8 \%$ up to September 2020. Our data are similar to those

Table 1 Baseline demographics and clinical characteristics stratified by COVID-19 severity

\begin{tabular}{|c|c|c|c|c|c|}
\hline & $\begin{array}{l}\text { All patients } \\
(n=122)\end{array}$ & $\begin{array}{l}\text { COVID-19 patients } \\
(n=51)\end{array}$ & $\begin{array}{l}\text { Non-severe COVID-19 } \\
(n=36)\end{array}$ & Severe COVID-19 $(n=15)$ & $\mathbf{p}$ \\
\hline Age (years), mean $\pm S D$ & $51.6 \pm 16.8$ & $53.5 \pm 17.1$ & $49.8 \pm 15.3$ & $62.5 \pm 18.2$ & 0.014 \\
\hline Male, $n(\%)$ & $74(60.7)$ & $32(66.7)$ & $22(61.1)$ & $10(66.7)$ & 0.708 \\
\hline Hypertension, $n(\%)$ & $88(72.1)$ & $35(68.6)$ & $23(63.9)$ & $12(80.0)$ & 0.259 \\
\hline Diabetes Mellitus, $n(\%)$ & $56(45.9)$ & $25(49.0)$ & $18(50.0)$ & $07(46.7)$ & 0.828 \\
\hline $\begin{array}{l}\text { Cardiovascular disease, } n \\
(\%)\end{array}$ & $16(13.1)$ & $10(19.6)$ & $4(11.1)$ & $6(40.0)$ & 0.018 \\
\hline $\begin{array}{l}\text { Severe Obesity } \\
\quad\left(\text { BMI }>30 \mathrm{~kg} / \mathrm{m}^{2}\right), \mathrm{n}(\%)\end{array}$ & $6(4.9)$ & $4(7.8)$ & $2(5.6)$ & $2(13.3)$ & 0.571 \\
\hline $\begin{array}{l}\text { Dialysis vintage (months), } \\
\text { median(IQR) }\end{array}$ & $62(11-240)$ & $84(12-144)$ & $60(8-120)$ & $196(36-244)$ & 0.005 \\
\hline $\begin{array}{l}\text { Hemoglobin }(\mathrm{g} / \mathrm{dL}) \text {, mean } \\
\pm \mathrm{SD}\end{array}$ & $11.8 \pm 1.6$ & $11.8 \pm 1.7$ & $11.8 \pm 1.8$ & $12.0 \pm 1.4$ & 0.738 \\
\hline Albumin $(\mathrm{g} / \mathrm{dL})$, mean $\pm \mathrm{SD}$ & $4.1 \pm 0.4$ & $4.1 \pm 0.3$ & $4.1 \pm 0.3$ & $4.2 \pm 0.4$ & 0.236 \\
\hline $\begin{array}{l}\text { ICAM-1 (ng/mL), median } \\
\text { (IQR) }\end{array}$ & $184(142-242)$ & $190(159-241)$ & $185(151-248)$ & $207(173-237)$ & 0.725 \\
\hline $\begin{array}{l}\text { VCAM-1 (ng/mL), median } \\
\text { (IQR) }\end{array}$ & $1,230(1,125-1510)$ & $1,229(1,124-1,480)$ & $1,205(1,129-1,479)$ & $1,366(1,025-1,527)$ & 0.885 \\
\hline $\begin{array}{l}\mathrm{AGPT} 2(\mathrm{pg} / \mathrm{mL}), \text { median } \\
\text { (IQR) }\end{array}$ & $1.34(0.72-2.10)$ & $1.48(0.76-2.23)$ & $1.56(0.67-2.31)$ & $1.20(0.76-1.94)$ & 0.522 \\
\hline $\begin{array}{l}\text { Syndecan-1 }(\mathrm{ng} / \mathrm{mL}), \\
\text { median }(\mathrm{IQR})\end{array}$ & $162(117-276)$ & $188(116-310)$ & $141(106-215)$ & $345(306-381)$ & $<0.001$ \\
\hline
\end{tabular}


Table 2 Multiple mediation analyses for severe COVID-19 according to age and dialysis vintage and with syndecan- 1 as Mediator

\begin{tabular}{|c|c|c|}
\hline Exposure variable & Crude OR $(95 \% \mathrm{CI})^{*}$ & $\begin{array}{l}\text { Adjusted OR }(95 \% \\
\text { CI)*-model } 1-\end{array}$ \\
\hline \multicolumn{3}{|l|}{ Age, per each year } \\
\hline Total effect of older age & $1.05(1.01-1.10)$ & $1.07(1.01-1.13)$ \\
\hline ACME of higher syndecan-1 & $1.05(1.01-2.96)$ & $1.06(1.02-4.11)$ \\
\hline ADE of older age & $1.00(0.94-1.07)$ & $1.01(0.93-1.10)$ \\
\hline \multicolumn{3}{|l|}{ Dialysis Vintage, per each 10 months } \\
\hline Total effect of higher dialysis vintage & $1.12(1.04-1.21)$ & $1.10(1.02-1.21)$ \\
\hline ACME of higher syndecan-1 & $1.10(1.03-4.89)$ & $1.08(1.03-6.67)$ \\
\hline ADE of higher dialysis vintage & $1.12(0.99-1.25)$ & $0.98(0.87-1.10)$ \\
\hline \multicolumn{3}{|c|}{$\begin{array}{l}A C M E \text { average causal mediation effect-a variable that explains how much of the putative effect of the } \\
\text { variable on COVID- } 19 \text { severity is explained by the possible effect of the mediator, } A D E \text { average direct } \\
\text { effect-a variable that explains how much of the putative effect of the variable on COVID-19 severity is } \\
\text { still explained by the variable after considering the effect of any given mediator, OR odds ratio. Model } 1 \text { : } \\
\text { adjusted for age, gender, hypertension, diabetes mellitus, cardiovascular disease, dialysis vintage, obesity, } \\
\text { hemoglobin and serum albumin }\end{array}$} \\
\hline
\end{tabular}

Our study has several limitations. First, we measured baseline endothelium-related biomarkers six months before the first COVID-19 case was detected in our cohort and we were unable to measure the syndecan-1 levels at the time of infection; however, the stability of such biomarkers can be determined by a high correlation between our samples collected in 2016 and those collected in 2019. Second, although we performed the ELISA test to detect COVID-19 antibodies in all participants, some lack of knowledge persists about the actual sensitivity of serological tests to diagnose previously asymptomatic infections in patients infected by COVID-19. In a recent study [7] carried out in hemodialysis patients, of 79 PCR-positive patients, only 2 were seronegative. It has also been suggested that up to $40 \%$ of asymptomatic individuals that were initially seropositive became seronegative in the early convalescent phase. However, another populationbased study demonstrated that over $90 \%$ of quantitative polymerase-chain-reaction-positive individuals tested positive at antibody assays and remained seropositive for 4 months after the diagnosis, with no decrease in antibody levels [9]. Finally, our criteria for defining severe COVID-19 were based on need for hospital admission, which depends on the assistant physician's criteria.

In conclusion, when analyzing several endotheliumrelated biomarkers prior to the SARS-Cov-2 infection, syndecan-1 was independently associated with severe COVID-19. Moreover, it seems to mediate the negative effects of age and dialysis vintage on COVID-19 severity in a cohort of maintenance HD patients. 


\section{Declarations}

Conflict of interest The authors have no conflict of interest.

Ethical statement This study was approved by the local Ethics Committee and was performed according to the Declaration of Helsinki. Participants received an explanatory statement and gave their written informed consent to participate in the study.

\section{References}

1. Organization GWH. WHO coronavirus disease (COVID-19) dashboard. https://covid19.who.int/. Accessed 12 Sept 2020

2. Varga Z, Flammer AJ, Steiger P et al (2020) Endothelial cell infection and endotheliitis in COVID-19. Lancet 395(10234):14171418. https://doi.org/10.1016/S0140-6736(20)30937-5

3. de Medeiros CMMF, da Silva BRD, Costa BG et al (2020) Cognitive impairment, endothelial biomarkers and mortality in maintenance haemodialysis patients: a prospective cohort study. Nephrol Dial Transplant. https://doi.org/10.1093/ndt/gfaa040

4. Leite AR, Borges-Canha M, Cardoso R, Neves JS, Castro-Ferreira R, Leite-Moreira A (2020) Novel biomarkers for evaluation of endothelial dysfunction. Angiology 71(5):397-410. https://doi. org/10.1177/0003319720903586
5. Grillet F, Behr J, Calame P, Aubry S, Delabrousse E (2020) Acute pulmonary embolism associated with COVID-19 pneumonia detected with pulmonary CT angiography. Radiology 296(3):E186-E188. https://doi.org/10.1148/radiol.2020201544

6. Hayes A (2013) Introduction to mediation, moderation, and conditional process analysis. Guilford, New York, pp 3-4 (978-1-60918-230-4)

7. Clarke C, Prendecki M, Dhutia A et al (2020) High prevalence of asymptomatic COVID-19 infection in hemodialysis patients detected using serologic screening. J Am Soc Nephrol. https:// doi.org/10.1681/ASN.2020060827

8. Koch J, Idzerda NMA, Dam W, Assa S, Franssen CFM, van den Born J (2019) Plasma syndecan-1 in hemodialysis patients associates with survival and lower markers of volume status. Am J Physiol Physiol 316(1):F121-F127. https://doi.org/10.1152/ajpre nal.00252.2018

9. Gudbjartsson DF, Norddahl GL, Melsted P et al (2020) Humoral immune response to SARS-CoV-2 in Iceland. N Engl J Med. https://doi.org/10.1056/NEJMoa2026116

Publisher's Note Springer Nature remains neutral with regard to jurisdictional claims in published maps and institutional affiliations. 